\title{
Interaction of elemental mercury with selenium surfaces: Model experiments for investigations of superheavy elements copernicium and flerovium
}

\begin{abstract}
Names of the authors: Nadine Mariel Chiera, Nikolay Viktorovich Aksenov, Gospodin Apostolov Bozhikov, Victor Ivanovich Chepigin, Sergei Nikolaevich Dmitriev, Rugard Dressler, Robert Eichler, Viacheslav Yakovlevich Lebedev, Alexander Shavkatovich Madumarov, Oleg Nikolaevich Malyshev, Dave Piguet, Viacheslav Michailovich Popov, Alexei Valentinovich Sabelnikov, Patrick Steinegger, Alexander Igorevich Svirikhin, Andreas Türler, Grigori Konstantinovich Vostokin, Alexander Vögele, Alexander Vladimirovich Yeremin.

Title: Interaction of elemental mercury with selenium surfaces: Model experiments for investigations of superheavy elements copernicium and flerovium

Affiliation(s) and address(es) of the authors:

Nadine Mariel Chiera: University of Bern, 3012 Bern, Switzerland \& Paul Scherrer Institute, 5232 Villigen, Switzerland. e-mail: nadine-mariel.chiera@psi.ch

Nikolay Viktorovich Aksenov: Flerov Laboratory of Nuclear Reactions JINR, 141980 Dubna, Russia. e-mail: nikolay.aksenov@jinr.ru

Gospodin Apostolov Bozhikov: Flerov Laboratory of Nuclear Reactions JINR, 141980 Dubna, Russia \& Institute for Advanced Physical Studies, 1618 Sofia, Bulgaria. e-mail: bozhikov@jinr.ru Victor Ivanovich Chepigin: Flerov Laboratory of Nuclear Reactions JINR, 141980 Dubna, Russia. e-mail: chepigin@sunvas.jinr.ru

Sergei Nikolaevich Dmitriev: Flerov Laboratory of Nuclear Reactions JINR, 141980 Dubna, Russia. e-mail: dmitriev@jinr.ru
\end{abstract}

Rugard Dressler: Paul Scherrer Institute, 5232 Villigen, Switzerland. e-mail: rugard.dressler@psi.ch 
Robert Eichler: University of Bern, 3012 Bern, Switzerland \& Paul Scherrer Institute, 5232 Villigen, Switzerland. e-mail: robert.eichler@psi.ch

Viacheslav Yakovlevich Lebedev: Flerov Laboratory of Nuclear Reactions JINR, 141980 Dubna, Russia. e-mail: alebedev@ nrmail.jinr.ru

Alexander Shavkatovich Madumarov: Flerov Laboratory of Nuclear Reactions JINR, 141980 Dubna, Russia. e-mail: $\underline{\text { alex @ madumarov.me }}$

Oleg Nikolaevich Malyshev: Flerov Laboratory of Nuclear Reactions JINR, 141980 Dubna, Russia. e-mail: malyshev@sunvas.jinr.ru

Dave Piguet: Paul Scherrer Institute, 5232 Villigen, Switzerland. e-mail: david.piguet@psi.ch

Viacheslav Michailovich Popov: Flerov Laboratory of Nuclear Reactions JINR, 141980 Dubna, Russia. e-mail: vmpopov@jinr.ru

Alexei Valentinovich Sabelnikov: Flerov Laboratory of Nuclear Reactions JINR, 141980 Dubna, Russia. e-mail: alexei.Sabelnikov@jinr.ru

Patrick Steinegger: University of Bern, 3012 Bern, Switzerland \& Paul Scherrer Institute, 5232 Villigen, Switzerland. e-mail: steinegger@jinr.ru

Alexander Igorevich Svirikhin: Flerov Laboratory of Nuclear Reactions JINR, 141980 Dubna, Russia.e-mail: sasha@sunvas.jinr.ru

Andreas Türler: University of Bern, 3012 Bern, Switzerland \& Paul Scherrer Institute, 5232

Villigen, Switzerland. e-mail: andreas.tuerler@psi.ch

Grigori Konstantinovich Vostokin: Flerov Laboratory of Nuclear Reactions JINR, 141980 Dubna, Russia. e-mail: vostokin@flnr.jinr.ru

Alexander Vögele: Paul Scherrer Institute, 5232 Villigen, Switzerland. e-mail: alexander.voegele@psi.ch

Alexander Vladimirovich Yeremin: Flerov Laboratory of Nuclear Reactions JINR, 141980 Dubna, Russia. e-mail: eremin@jinr.ru 
E-mail address of the corresponding author: robert.eichler@psi.ch 


\section{Interaction of elemental mercury with selenium surfaces:}

\section{Model experiments for investigations of superheavy elements}

\section{copernicium and flerovium}

N.M. Chiera ${ }^{1,2}$, N. V. Aksenov ${ }^{3}$, Y. V. Albin ${ }^{3}$, G. A. Bozhikov ${ }^{3,4}$, V. I. Chepigin ${ }^{3}$, S. N. Dmitriev ${ }^{3}$, R. Dressler ${ }^{1}$, R. Eichler ${ }^{1,2}$, V. Ya. Lebedev ${ }^{3}$, A. Madumarov³ , O. N. Malyshev ${ }^{3}$, D. Piguet ${ }^{1}$, Y.A. Popov $^{3}$, A. V. Sabelnikov ${ }^{3}$, P. Steinegger ${ }^{1,2}$, A. I. Svirikhin ${ }^{3}$, A. Türler ${ }^{1,2}$, G. K. Vostokin ${ }^{3}$, A. Vögele $^{1}$, A. V. Yeremin ${ }^{3}$.

${ }^{1}$ Department of Chemistry and Biochemistry, University of Bern, Freiestrasse 3, 3012 Bern, Switzerland.

${ }^{2}$ Laboratory of Radiochemistry, Paul Scherrer Institute, Villigen PSI Ost, 5232 Villigen, Switzerland.

${ }^{3}$ Flerov Laboratory of Nuclear Reactions, Joint Institute Nuclear Research, 141980 Dubna, Moscow region, Russia.

${ }^{4}$ Institute for Advanced Physical Studies, New Bulgarian University, Montevideo Street 21, 1618 Sofia, Bulgaria. 


\begin{abstract}
The adsorption behavior of ${ }^{197} \mathrm{Hg}$ and ${ }^{183-185} \mathrm{Hg}$ on red amorphous selenium (red a-Se) and trigonal selenium (t-Se) was investigated experimentally by off-line and on-line gas chromatographic methods, in preparation of a sensitive chemical separation and characterization of the transactinides copernicium $(\mathrm{Cn}, \mathrm{Z}=112)$ and flerovium $(\mathrm{Fl}, \mathrm{Z}=114)$. Monte-Carlo simulations of a diffusion controlled deposition were in good agreement with the experimental results, assuming as interaction limits $-\Delta \mathrm{H}_{\mathrm{ads}}{ }^{\text {red } \mathrm{a}-\mathrm{Se}}(\mathrm{Hg})>85 \mathrm{~kJ} / \mathrm{mol}$, and $-\Delta \mathrm{H}_{\mathrm{ads}}{ }^{\mathrm{t}} \mathrm{Se}(\mathrm{Hg})<60 \mathrm{~kJ} / \mathrm{mol}$. Both Se allotropes can be used as stationary surfaces in comparative gas-chromatographic chemical investigations of $\mathrm{Cn}$ and $\mathrm{Fl}$.
\end{abstract}

\title{
Keywords
}

Mercury, adsorption, selenium surface, isothermal gas chromatography, superheavy elements, model experiments for $\mathrm{Cn}$ and $\mathrm{Fl}$.

\section{Introduction}

Superheavy elements (SHEs, also referred to as transactinide elements), defined as all elements with a proton number $Z>103$, represent one extreme limit of the existent atomic matter. So far, heavy ion induced nuclear fusion reactions allowed for the artificial synthesis of SHEs up to $\mathrm{Z}=118$ [1]. Along with the challenging production of SHEs, relativistic atomic and molecular models were developed as well, suggesting how and to what extent relativistic effects influence the physical and chemical properties of the elements [2]. Whereas these effects are negligible for lighter elements, they may cause deviations from the periodicity of the chemical properties established by the periodic table in case of the heavier ones [2]. Since direct measurements of the electronic configuration can so far not be performed, the chemical behavior of the SHEs is studied with single short-lived atoms, in so-called "one-atom-at-a-time" radiochemical experiments [3]. 
For the investigation of the chemical properties of the SHEs, the strategy of a direct comparison of their chemical behavior with that of their lighter homologues under identical conditions is followed [4]. Exciting examples of radiochemical studies with SHEs are the recent investigations involving copernicium $(\mathrm{Cn}, \mathrm{Z}=112)$ and flerovium $(\mathrm{Fl}, \mathrm{Z}=114)$, positioned in group 12 and 14 of the periodic table, respectively. Being both SHEs characterized by short half-lives and a high volatility, gas chromatography is used [5]. The high volatility of mercury, the lighter homologue of copernicium, renders this element suitable for comparative gas chromatographic studies simultaneously with $\mathrm{Cn}$ and $\mathrm{Fl}$. In gas adsorption chromatographic studies with gold as a stationary surface, Cn exhibited a metallic character typical for group 12 elements. However, due to direct relativistic effects, the superheavy element revealed as well a less pronounced binding and a higher volatility than its lighter homologue mercury [6]. Fl was theoretically predicted to be more reactive and less volatile than $\mathrm{Cn}$, thus being chemically distinguishable [7]. Nevertheless, gas adsorption chromatographic studies revealed surprising results: First experiments pointed to Fl being more volatile than $\mathrm{Cn}$, forming only a weak physisorption bond on a gold surface [8]. However, later experiments pointed to the formation of a metal-metal bond between $\mathrm{Fl}$ and $\mathrm{Au}$ at least as strong as that of $\mathrm{Cn}$ with the same surface [9]. Thus, an unambiguous chemical characterization of Fl is still pending.

Previously, sulfur was pointed out to be a good candidate as a chromatographic surface for gas adsorption experiments with copernicium and flerovium [5]. However, the high kinetic interaction hindrance at room temperature of $\mathrm{Hg}$ toward the sulfur surface prevented the further development of this chemical system [Chiera N. M., accepted for publication in Journal Radioanalytical and Nuclear Chemistry, 2016]. It was suggested that the chemical irreversible interaction between mercury and sulfur, both in their elemental state, is promoted at temperatures higher than $140^{\circ} \mathrm{C}$ $[10,11]$. These temperatures are far beyond those allowed for a safe operation of the Positive Implanted N-type silicon (PIN) $\alpha$-detectors, commonly used in on-line gas chromatographic studies with SHEs [12]. Nevertheless, high-temperature resistant diamond-based solid state detectors for $\alpha$-spectroscopic measurements in future radiochemical studies of SHEs are currently under development [13]. However, even with this new technology, the exploration of the interaction $\mathrm{Hg} / \mathrm{S}$ in gas-solid adsorption experiments can be performed only at temperatures below sulfur's melting point (i.e., $\mathrm{T}_{\text {m.p. }}=115.2^{\circ} \mathrm{C}$ ). In fact, at higher temperatures the $\mathrm{Hg} / \mathrm{S}$ 
interaction has to be studied in a gas-liquid chromatographic system under a dynamic gas flow, requiring a totally different model approach.

In this study, selenium was chosen as a stationary chromatographic surface for gas adsorption studies, to allow for the preparation of a sensitive chemical separation and characterization of $\mathrm{Cn}$ and Fl. In fact, extrapolative predictions [14], in which thermochemical state functions are correlated mutually, revealed that the stability trends of the selenide formation in the solid state are predicted to be opposite for groups 12 and 14 (Fig. 1). In other words, the formation of Fl-Se is expected to be favored or at least similar to the homologous selenides, whereas the interaction between $\mathrm{Cn}$ and selenium is expected to be weaker than the one of $\mathrm{Hg}$ with $\mathrm{Se}$, following the thermodynamic stability trend $\mathrm{CnSe}<\mathrm{HgSe}<\mathrm{FlSe}$. These thermodynamic trends are based on the sublimation enthalpy values $\Delta \mathrm{H}_{\text {subl }}{ }^{298}(\mathrm{Cn})=36 \pm 10 \mathrm{~kJ} / \mathrm{mol}[5]$ and $\Delta \mathrm{H}_{\text {subl }}{ }^{298}(\mathrm{Fl})=25^{+22}{ }_{-10} \mathrm{~kJ} / \mathrm{mol}$ [5], deduced from the empirical correlation $-\Delta \mathrm{H}_{\text {ads Au }}{ }^{298}(\mathrm{M})=(1.32 \pm 0.05) \cdot \Delta \mathrm{H}_{\text {subl }}{ }^{298}(\mathrm{M})+(4.18$ \pm 3.68 ), $\mathrm{kJ} / \mathrm{mol}$, where $\mathrm{M}=\mathrm{Cn}$ or Fl [5]. Similar trends for the standard enthalpies of formation of $\mathrm{CnSe}_{(\mathrm{s})}$ and $\mathrm{FlSe}_{(\mathrm{s})}$ are obtained considering the standard enthalpies of formation of mono-atomic gases, i.e., $\Delta \mathrm{H}_{\mathrm{f}}{ }^{\circ}(\mathrm{Cn})=39 \pm 3 \mathrm{~kJ} / \mathrm{mol}[15]$ and $\Delta \mathrm{H}_{\mathrm{f}}{ }^{\circ}(\mathrm{Fl})=190 \pm 18 \mathrm{~kJ} / \mathrm{mol}$ [15]. These values were obtained through an extrapolation, correlating the surface energies of elemental solids of groups 12 and 14 with their respective enthalpies of sublimation. However, most recent solid state calculations of cohesive energies predict $E_{\mathrm{coh}}=109 \mathrm{~kJ} / \mathrm{mol}$ for $\mathrm{Cn}[16]$, and $\mathrm{E}_{\mathrm{coh}}=48 \mathrm{~kJ} / \mathrm{mol}$ for Fl [17]. In this case, the thermodynamic stability of the selenide formation in the solid state follows the trend $\mathrm{Hg}<\mathrm{Cn}<\mathrm{Fl}$ (see Fig. 1). Since theoretical relativistic density functional calculations of these chemical systems are still missing, experimental benchmark data are required.

Among the various morphologies of elemental Se, recent studies reported red amorphous selenium (red a-Se) to be the best sorbent for mercury vapor, partly due to the high surface-to-mass ratios of the nanoparticles [18]. However, the interaction strength was not quantified. The structure of the red a-Se allotrope was frequently discussed during the previous decades (see e.g., [19, 20]). This has led to the general agreement that its composition is made of short selenium chains and $\mathrm{Se}_{\mathrm{n}}$-ring clusters, the ratio of which depends on the deposition method and on the temperature at which the substrate is held [21, 22]. Recently the "disordered chain" model was developed [23], in which the amorphous phase is composed of twisted molecular structures having both a chainand ring-like configuration. Upon heating to temperatures higher than $37^{\circ} \mathrm{C}$, red a-Se transforms 
to the black amorphous Se allotrope (black a-Se), with the latter consisting of thousands of selenium atoms arranged in disordered polymeric molecules [24]. Both allotropes are metastable, and spontaneously undergo a transformation to the crystalline trigonal selenium (t-Se), which is the most thermodynamically stable allotrope at standard ambient temperature and pressure conditions up to its melting point at $217^{\circ} \mathrm{C}$. This allotropic transformation, called "crystallization process", is strictly connected to the structure of the amorphous phase and on the environmental conditions (e.g. temperature, humidity, impurities, and light exposure [25, 26]). Trigonal Se consists of helical polymeric chains with a trans-configuration arrangement of the Se atoms; contiguous atoms form single covalent bonds, while each chain interacts with the neighboring one through Van der Waals forces [27]. As the thermodynamically most stable allotrope, t-Se is the least reactive solid form of Se and unlike all the other allotropes it does not dissolve in $\mathrm{CS}_{2}$ [27].

Since the reactivity of these solid phases of elemental selenium varies, off-line and on-line gas chromatographic model experiments were conducted with stationary surfaces of different allotropic forms of selenium. For a homogeneous coating of the quartz tubes and the silicon detector surfaces, a Se vapor transport deposition technique was applied [28].

Here, we present model experiments using different radioisotopes of $\mathrm{Hg}$, with the $\mathrm{Hg}-\mathrm{Se}_{(\mathrm{s})}$ formation as an important comparative experimental value for the later assessment of the $\mathrm{Cn}-\mathrm{Se}_{(\mathrm{s})}$ and $\mathrm{Fl}_{-} \mathrm{Se}_{(\mathrm{s})}$ interactions (see Fig.1). On the basis of the experimental results, Monte-Carlo (MC) simulations were performed using the microscopic kinetic model for gas adsorption chromatography on an atomic scale [29]. These simulations led to limits for the adsorption enthalpies $\left(-\Delta \mathrm{H}_{\mathrm{ads}}\right)$ at zero surface coverage of $\mathrm{Hg}$ on surfaces covered with different selenium allotropes.

Assessing the chemical interaction behavior of $\mathrm{Hg}$ with various Se allotropes permits the selection of the experimental conditions that need to be applied in the gas adsorption investigations with SHEs. 


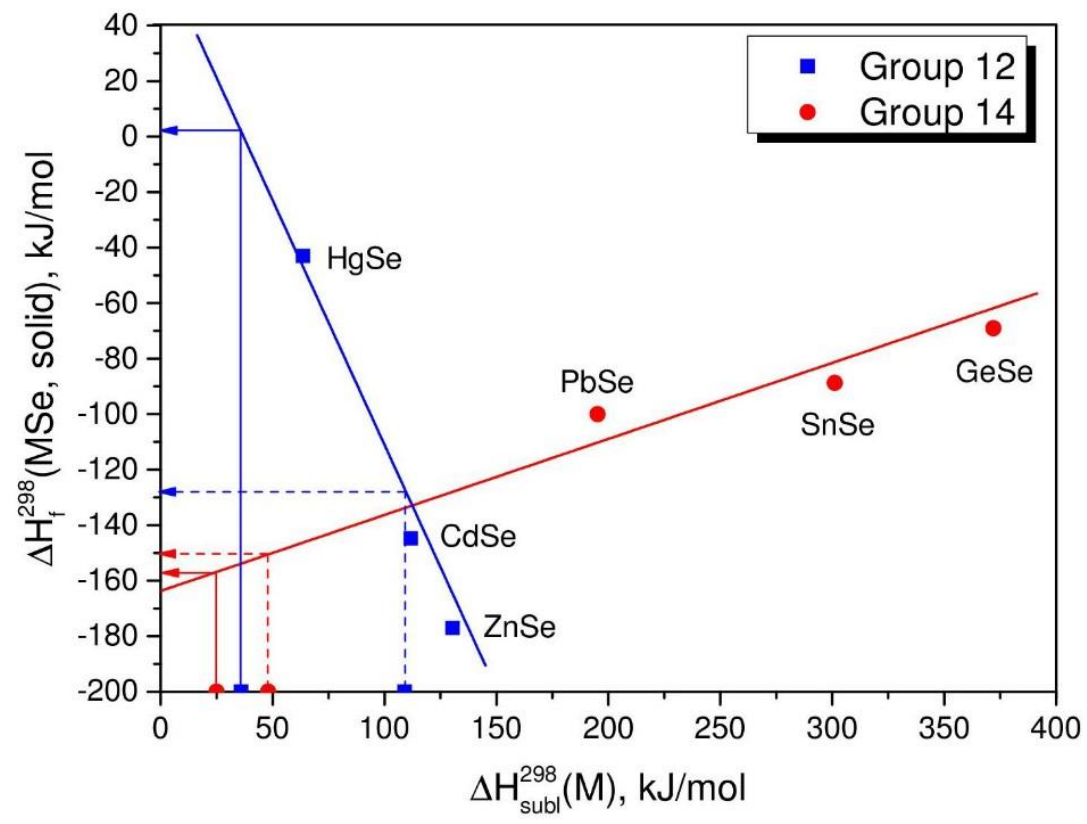

Fig. 1 Thermodynamic stability trends for the selenide formation (solid state) for groups 12 (blue) and 14 (red), obtained applying a linear regression analysis (solid lines). The sublimation enthalpies $\Delta \mathrm{H}_{\text {subl. }}{ }^{298}(\mathrm{M})$, and the standard enthalpies of formation of the selenides in the solid state $\Delta \mathrm{H}_{\mathrm{f}}{ }^{298}\left(\mathrm{MSe}\right.$, solid) with $\mathrm{M}=\mathrm{Hg}, \mathrm{Cd}, \mathrm{Zn}, \mathrm{Ge}, \mathrm{Sn}, \mathrm{Pb}$ are taken from [30, 31]. $\Delta \mathrm{H}_{\text {subl. }}{ }^{298}(\mathrm{Cn})$ and $\Delta \mathrm{H}_{\text {subl. }}{ }^{298}(\mathrm{Fl})$, leading to the extrapolated values $\Delta \mathrm{H}_{\mathrm{f}}{ }^{298}\left(\mathrm{CnSe}\right.$ ) and $\Delta \mathrm{H}_{\mathrm{f}}{ }^{298}(\mathrm{FlSe})$ (solid blue and red arrows, respectively), are deduced from the empirical correlation reported in [5]. The extrapolated $\Delta \mathrm{H}_{\mathrm{f}}^{298}(\mathrm{CnSe})$ and $\Delta \mathrm{H}_{\mathrm{f}}^{298}(\mathrm{FlSe})$ values, based on the most recent solid state theoretical calculations of cohesive energies [16,17], are indicated (dashed blue and red arrows, respectively).

\section{Experimental}

\subsection{Off-line isothermal chromatography}

Quartz columns $\left(\mathrm{d}_{\mathrm{in}}=0.4 \mathrm{~cm}, 1=10 \mathrm{~cm}\right)$ were coated with red a-Se applying the vapor transport deposition method described in [28]. The coated selenium columns were stored for a maximum of 24 hours in complete darkness and under inert atmosphere (dried Ar, 99.9990 vol. \% purity) prior to the respective $\mathrm{Hg}$ deposition experiments. Pure t-Se covered columns were obtained through a 
thermal treatment of the columns coated with red a-Se, applying a three step heating process at $100^{\circ} \mathrm{C}, 110^{\circ} \mathrm{C}$, and $150^{\circ} \mathrm{C}$, as suggested in $[26,32]$. Subsequently, these columns were rinsed with $\mathrm{CS}_{2}$ to remove the remnants of the other allotropes and they were finally heated to $50^{\circ} \mathrm{C}$ in order to evaporate the solvent. To quantify the obtained crystallization grade, a quartz column was coated with red a-Se containing ${ }^{75} \mathrm{Se}\left(\mathrm{t}_{1 / 2}=119.78 \mathrm{~d}\right.$; main $\gamma$-lines: $\left.136 \mathrm{keV}(59.2 \%), 265 \mathrm{keV}(59.8 \%)\right)$ as a radiotracer. ${ }^{75} \mathrm{Se}$ was produced by the irradiation of the initial elemental gray Se (purity $>99.999 \%$, Fluka Chemicals) with thermal neutrons using the rabbit system for neutron activation installed at the spallation neutron source SINQ at the Paul Scherrer Institute (https://www.psi.ch/nis/). The amount of the radioactive ${ }^{75} \mathrm{Se}$ isotope deposited in the silica column was determined via measuring the specific $\gamma$-activity with a high-purity germanium (HPGe) $\gamma$-ray detector in conjunction with the Canberra's Genie $2 \mathrm{k}^{\circledR}$ data acquisition and analysis software. The so-coated red a-Se column was successively exposed to the crystallization treatment described above. Then, the specific $\gamma$-activity of the selenium coverage was measured again, allowing for calculating the quantity of ${ }^{75} \mathrm{Se}$ in the column after the heating and $\mathrm{CS}_{2}$ rinsing process. In this manner, $\mathrm{a} \approx 70 \%$ conversion of the initial red a-Se coating into the trigonal allotrope was deduced. However, the Se amount after the crystallization procedure is not spread uniformly on the quartz surface, covering only an average of $\approx 40 \%$ as deduced from optical microscopy.

The carrier-free ${ }^{197} \mathrm{Hg}\left(\mathrm{t}_{1 / 2}=64 \mathrm{~h}\right.$; main $\gamma$-line: $\left.77 \mathrm{keV}(18.7 \%)\right)$ was produced by the irradiation of natural Tl (purity $>99.999 \%$, Sigma-Aldrich), this time making use of the fast neutrons at the Neutron Irradiation Facility (NIS) at the SINQ. ${ }^{197} \mathrm{Hg}$ was volatilized by heating the irradiated Tl sample up to $350^{\circ} \mathrm{C}$ inside a quartz column $\left(\mathrm{d}_{\text {in }}=0.4 \mathrm{~cm}, 1=50 \mathrm{~cm}\right)$. The released mercury tracer was then transported by a helium gas flow (99.9990 vol.-\% purity) to the Se columns kept at room temperature (see schematic in Fig. 2). The helium gas flow rate was controlled by a mass flow controller (Series 5850E, Brooks Instruments). No loss of ${ }^{197} \mathrm{Hg}$ was observed during the transport of such carrier-free amounts of $\mathrm{Hg}$ through a quartz column, since $\mathrm{Hg}$ does not adsorb on quartz at ambient temperatures [33]. The deposition pattern of the radioactive ${ }^{197} \mathrm{Hg}$ along the red a-Se and t-Se columns was determined by $\gamma$-ray spectrometry using a HPGe detector positioned behind a lead collimator (window size $1.0 \times 1.0 \mathrm{~cm}^{2}$, lead thickness $1 \mathrm{~cm}$ ). The data acquisition and analysis system Canberra Genie $2 \mathrm{k}^{\circledR}$ enabled the quantification of the ${ }^{197} \mathrm{Hg}$ radioactive activity for each centimeter of the column. 


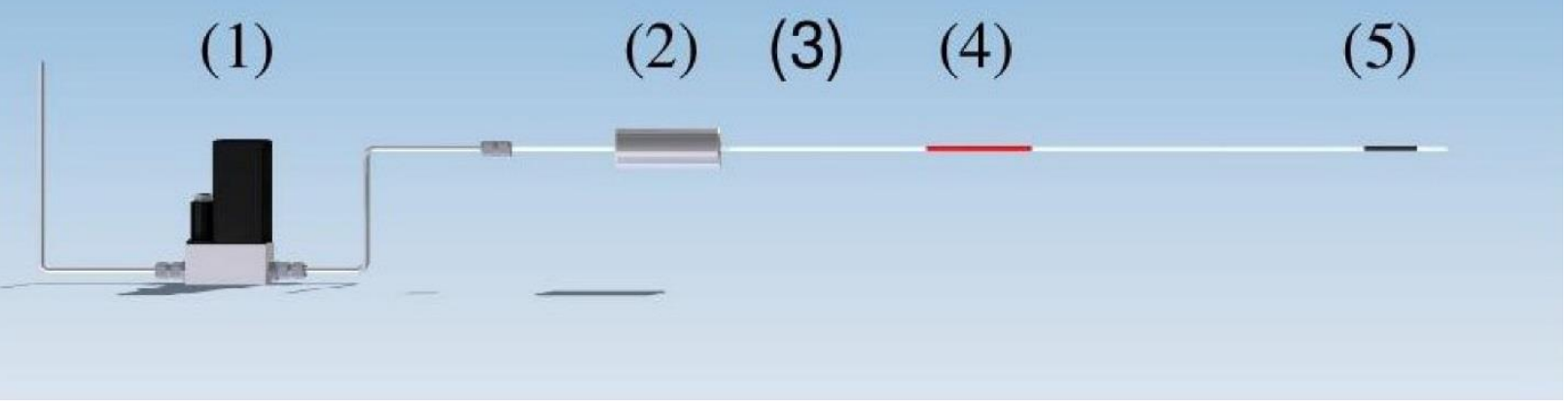

Fig. 2 Schematics of the experimental off-line deposition setup. The He gas flow, regulated by a mass flow controller (1), is passed through a quartz tube (3). The irradiated $\mathrm{Tl}$ sample is positioned inside this quartz tube and heated by means of a resistive oven kept at $350^{\circ} \mathrm{C}(2)$. The evaporated ${ }^{197} \mathrm{Hg}$ is then transported to the Se (trigonal or red amorphous) coated column part (4), while the ${ }^{197} \mathrm{Hg}$ which is not retained in (4) is ultimately captured in a charcoal trap (5).

\subsection{On-line chromatography}

On-line chromatographic experiments were performed with the Cryo-On-Line Detector (COLD) setup as described in $[34,35]$. Two lanthanide oxide targets $\left(\mathrm{Nd}_{2} \mathrm{O}_{3}\right.$ and $\mathrm{Nd}_{2} \mathrm{O}_{3} / \mathrm{Dy}_{2} \mathrm{O}_{3}$, used in Experiments A and B, respectively) were irradiated with a $276 \mathrm{MeV}^{48} \mathrm{Ca}$ ion beam, delivered from the U-400 cyclotron at the Flerov Laboratory of Nuclear Reactions (FLNR), Dubna. The ion beam energy was degraded to about $245 \mathrm{MeV}$ by a $4 \mu \mathrm{m}$ Ti vacuum window, a cooling gas slit, and the $2 \mu \mathrm{m}$ thick Ti target backing before entering the target material [36]. The short-lived $\alpha$-emitters ${ }^{183} \mathrm{Hg}\left(\mathrm{t}_{1 / 2}=9.4 \mathrm{~s}\right),{ }^{184} \mathrm{Hg}\left(\mathrm{t}_{1 / 2}=30.9 \mathrm{~s}\right)$, and ${ }^{185} \mathrm{Hg}\left(\mathrm{t}_{1 / 2}=49.1 \mathrm{~s}\right)$ were synthesized in the reaction ${ }^{\text {nat }} \mathrm{Nd}\left({ }^{48} \mathrm{Ca}\right.$, xn $)$, whereas the Dy admixture in case of the second target for Experiments B was used to synthesize radon isotopes, meant for a different purpose. The recoiling nuclear reaction products were thermalized in a recoil chamber, being internally covered with a quartz inlay and constantly flushed with a $1.6 \mathrm{~L} / \mathrm{min}$ inert carrier gas flow. After their thermalization, the reaction products were transported through a $4 \mathrm{~m}$ long perfluoroalkoxy (PFA®) Teflon capillary to the chromatographic detection system COLD. This setup allowed only volatile products to be 
transported from the production site to the detector array. All aerosol particles (produced e.g., by beam-induced sputtering processes) were stopped with a quartz-wool filter kept at a temperature of $850^{\circ} \mathrm{C}$ [37]. Before entering the recoil chamber and later on the detection system, the carrier gas was passed through a tantalum getter, heated up to $950^{\circ} \mathrm{C}$ in order to remove residual traces of water and oxygen. The COLD system consists of an array of 32 PIN diode detector pairs mounted in a stainless steel channel, thereby forming a rectangular gas chromatographic column (length $=32 \mathrm{~cm}$ ) with an open cross section of $0.12 \times 1.2 \mathrm{~cm}^{2}$. The PIN diode detectors together with a custom-made measurement system enabled a time-correlated event-by-event spectroscopy of $\alpha$-particles, emitted during the radioactive decay of species deposited on the inner surfaces of the detector channel. One side of the detector pairs was in contact with a copper inlay worked into the top lid of the stainless steel channel, thereby providing the required optimum temperature distribution along the chromatographic channel. The isothermal conditions for the Se covered detectors at the entrance of the detector array were established by a copper block heated with a thermostat. A temperature gradient along the Au covered part of COLD was established between the heated copper block and the liquid nitrogen cooling mounted at the end of the channel. The temperature was monitored by a set of eight Pt100 thermoresistors installed asymmetrically along the copper inlay (see Table 1). The experimental conditions for Experiments A and B are depicted in Table 2.

The selenium coverage of the detectors was obtained through the vapor transport deposition method of Se vapor quenched at liquid nitrogen temperatures [28]. A set of Se covered diodes with an area density of $200 \mu \mathrm{g} / \mathrm{cm}^{2}$ was produced. $\alpha$-spectroscopic measurements of a standard mixed radionuclide source $\left({ }^{239} \mathrm{Pu},{ }^{241} \mathrm{Am}\right.$, and $\left.{ }^{244} \mathrm{Cm}\right)$ in conjunction with the Advanced AlphaSpectrometric (AASIfit) simulation package [38] allowed for the estimation of a layer thickness of $0.5 \mu \mathrm{m}$. After their preparation, the detectors were stored in a high density polyethylene container filled with Ar (99.9990 vol.-\% purity). The diodes were subdivided into two groups, and stored for 5.5 and 9 weeks, respectively. Two diodes covered with a $200 \mu \mathrm{g} / \mathrm{cm}^{2}$ thick Se layer were exposed to a thermal treatment at $45^{\circ} \mathrm{C}$. This led to the modification of their surface from the red a-Se to the black amorphous allotrope [26], being performed in order to assess the different reactivity of mercury toward the two amorphous allotropes. From optical microscopy analysis, the Se coverage was determined to be at maximum $50 \%$ of the diode surface. 
An X-ray diffraction study of the red a-Se surface aged for 5.5 weeks was carried out with a Bruker AXS D8 Advance X-Ray Diffractometer using $\mathrm{Cu}-\mathrm{K} \alpha$ radiation $(\mathrm{E}=8047.8 \mathrm{eV})$ in the 20-range from $20^{\circ}$ to $50^{\circ}$. On the same Se surface, a scanning electron microscopy examination was performed using a Zeiss Supra VP55 high resolution field emission scanning electron microscope. Table 3 lists the disposition and some of the characteristics of the detectors with selected surface coverages used in the Experiments A and B.

Table 1 Position of the eight Pt800 thermoresistors along the COLD array.

\begin{tabular}{|l|l|l|l|l|l|l|l|l|}
\hline Thermocouple & T1 & T2 & T3 & T4 & T5 & T6 & T7 & T8 \\
\hline Diode pair & 1 & 4 & 7 & 12 & 20 & 26 & 29 & 32 \\
\hline
\end{tabular}

Table 2 Experimental conditions for the on-line Experiments A and B.

\begin{tabular}{|c|c|c|c|c|c|c|c|c|c|c|c|}
\hline \multirow{2}{*}{\multicolumn{2}{|c|}{$\begin{array}{l}\text { Target } \\
\text { material }\end{array}$}} & \multirow{2}{*}{$\begin{array}{c}\text { Carrier } \\
\text { gas }\end{array}$} & \multirow{2}{*}{$\begin{array}{c}\text { Run } \\
\#\end{array}$} & \multicolumn{8}{|c|}{$\mathrm{T}\left({ }^{\circ} \mathrm{C}\right)$} \\
\hline & & & & $\mathrm{T} 1$ & $\mathrm{~T} 2$ & T3 & $\mathrm{T} 4$ & $\mathrm{~T} 5$ & T6 & $\mathrm{T} 7$ & T8 \\
\hline \multirow{4}{*}{ Exp.A } & \multirow{3}{*}{$\mathrm{Nd}_{2} \mathrm{O}_{3}$} & \multirow{5}{*}{$\mathrm{Ar}$} & 1 & 6 & 5.5 & 4.2 & 6.6 & 9.9 & 10.8 & 12.7 & 13.2 \\
\hline & & & 2 & 6.1 & 5.6 & 4.3 & 6.5 & 9.6 & 10.3 & 12.2 & 12.5 \\
\hline & & & 3 & 5.8 & 5.3 & 4.1 & 6.0 & 9.2 & 10.1 & 11.8 & 12.3 \\
\hline & \multirow{4}{*}{$\begin{array}{l}\mathrm{Nd}_{2} \mathrm{O}_{3} / \\
\mathrm{Dy}_{2} \mathrm{O}_{3}\end{array}$} & & 4 & 5.7 & 5.3 & 4.1 & 5.9 & 9.0 & 10.1 & 11.7 & 12.1 \\
\hline \multirow{3}{*}{ Exp.B } & & & 5 & 5.6 & 5.1 & 4.0 & 5.7 & 8.8 & 9.7 & 11.2 & 12.0 \\
\hline & & \multirow{2}{*}{$\begin{array}{l}\mathrm{Ar} / \mathrm{He} \\
70: 30\end{array}$} & & & & & & & & & \\
\hline & & & 1 & 47.8 & 49.3 & 52.6 & 33.7 & -22.7 & -74.6 & -106.2 & -139.6 \\
\hline
\end{tabular}

Table 3 Disposition of the detector pairs inside the COLD array (Q: quartz, B: black a-Se, R: red a-Se, Au: gold coverage). The storage time of the selenium covered PIN diodes is specified.

\begin{tabular}{llllllllllll|}
\multicolumn{1}{c|}{ Diode pair position in the COLD array } \\
1 & 2 & 3 & 4 & 5 & 6 & 7 & 8 & 9 & 10 & $11-32$ \\
\hline
\end{tabular}




\begin{tabular}{|c|c|c|c|c|c|c|c|c|c|c|c|c|}
\hline \multirow[t]{3}{*}{ Exp.A } & Coverage & $\mathrm{Q}$ & B & B & $\mathrm{R}$ & $\mathrm{R}$ & $\mathrm{R}$ & $\mathrm{R}$ & $\mathrm{R}$ & Q & $\mathrm{Q}$ & $\mathrm{Au}$ \\
\hline & $\begin{array}{l}\text { Se thickness, } \\
\mu \mathrm{g} / \mathrm{cm}^{2}\end{array}$ & - & 200 & 200 & 200 & 200 & 200 & 200 & 200 & - & - & - \\
\hline & $\begin{array}{l}\text { Se storage time, } \\
\text { weeks }\end{array}$ & - & 5.5 & 5.5 & 5.5 & 9 & 5.5 & 9 & 5.5 & - & - & - \\
\hline \multirow[t]{3}{*}{ Exp.B } & Coverage & Q & B & B & $\mathrm{R}$ & $\mathrm{R}$ & $\mathrm{R}$ & $\mathrm{R}$ & Q & Q & $\mathrm{Au}$ & $\mathrm{Au}$ \\
\hline & $\begin{array}{l}\text { Se thickness, } \\
\mu \mathrm{g} / \mathrm{cm}^{2}\end{array}$ & $\begin{array}{lll}- & \text { r }\end{array}$ & 200 & 200 & 200 & 200 & 100 & 100 & - & - & - & - \\
\hline & $\begin{array}{l}\text { Se storage time, } \\
\text { weeks }\end{array}$ & - & 5.5 & 5.5 & 5.5 & 9 & 5.5 & 9 & - & - & - & - \\
\hline
\end{tabular}

\section{Results and discussion}

\subsection{Off-line isothermal chromatography}

\subsubsection{Hg interaction towards red amorphous selenium}

The measured amounts of ${ }^{197} \mathrm{Hg}$ adsorbed in the red a-Se coated columns at two different experimental conditions led to the deposition patterns shown in Fig. 3 (grey bars). A spontaneous diffusion controlled deposition with a $100 \%{ }^{197} \mathrm{Hg}$ retention was observed in the chromatographic column kept isothermally at room temperature. However, the broadening of the initial deposition with changing the experimental conditions indicates that the $\mathrm{Hg} / \mathrm{red}$ a-Se interaction is a reversible adsorption. For this reason, MC simulations (see Fig. 3, red lines), based on the microscopic kinetic model for the adsorption process on a stationary surface from a laminar gas flow [29], were applied. This Monte-Carlo based data analysis approach allowed for estimating a lower limit of the standard adsorption enthalpy at zero surface coverage of $-\Delta \mathrm{H}_{\mathrm{ads}}{ }^{\text {red a- }}$ $\mathrm{Se}(\mathrm{Hg})>85 \mathrm{~kJ} / \mathrm{mol}$. The lower limit obtained in the performed isothermal experiment means that 
the interaction between $\mathrm{Hg}$ and the red a-Se surface is likely to be stronger. The best fitting to the experimental data was chosen minimizing the sum of the squares of the offsets between the simulated curve and the experimental one. In the simulations, 95\% coverage of the stationary surface with red a-Se was assumed. This degree of coverage was derived using an optical microscopy examination (Fig. 4) and a RGB (Red-Green-Blue) analysis performed with the Origin 2015 software package. The remaining 5\% was considered to be pure quartz column surface. The adsorption interaction enthalpy of $\mathrm{Hg}$ on quartz is known as $-\Delta \mathrm{H}_{\mathrm{ads}} \mathrm{SiO}^{2}(\mathrm{Hg})=42 \mathrm{~kJ} / \mathrm{mol}$ [39], leaving $-\Delta \mathrm{H}_{\mathrm{ads}}{ }^{\text {red a-Se }}(\mathrm{Hg})$ as the only free parameter in the simulations.

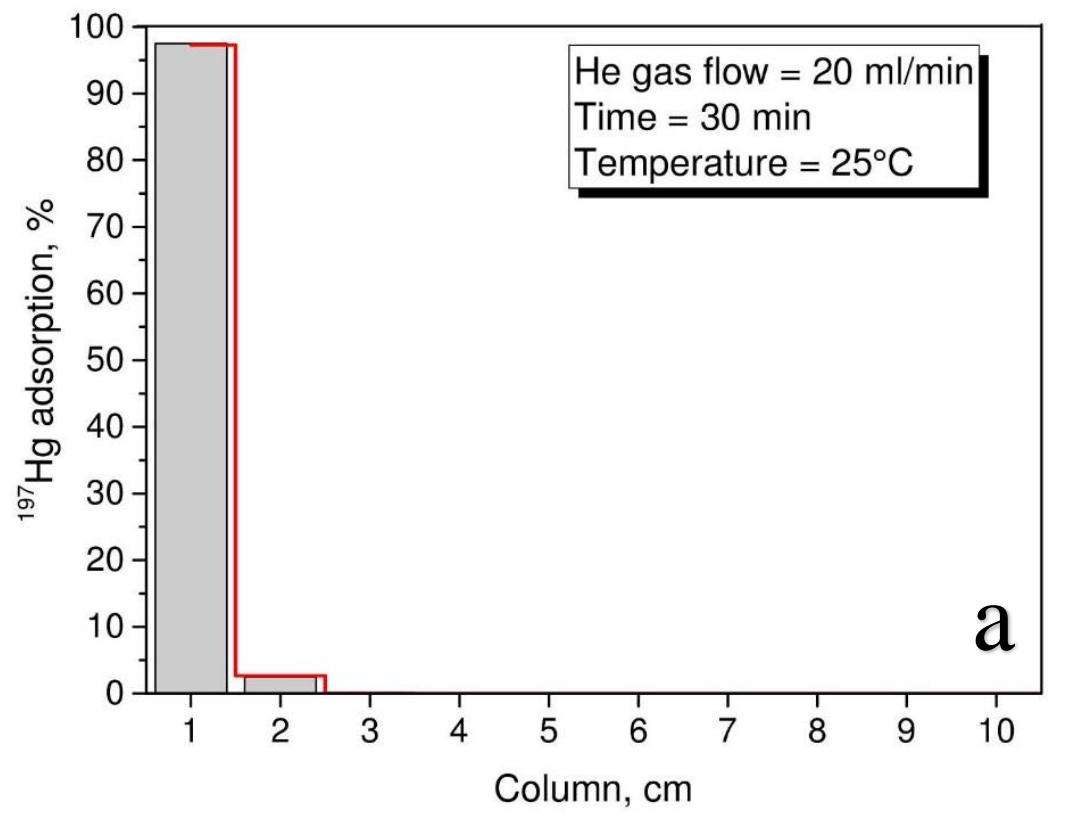




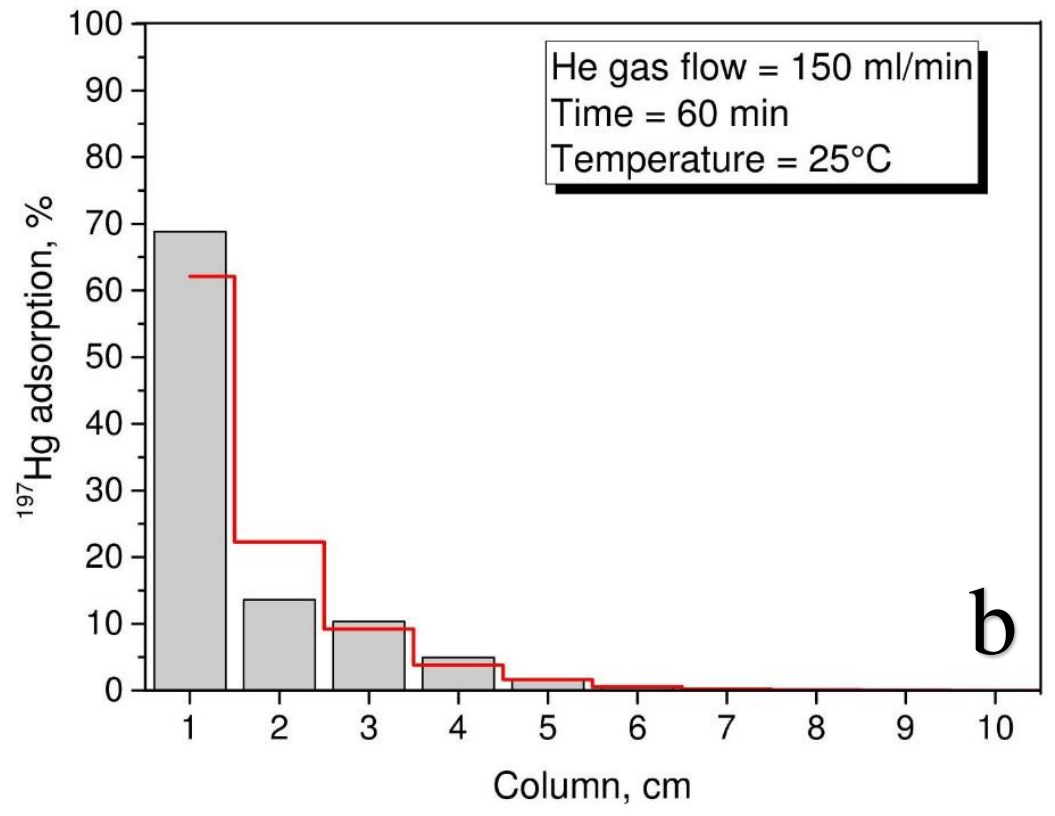

Fig. 3 Deposition pattern of ${ }^{197} \mathrm{Hg}$ (grey bars) at $\mathrm{T}=25^{\circ} \mathrm{C}$ applying a) a He gas flow of $20 \mathrm{~mL} / \mathrm{min}$ for $30 \mathrm{~min}$, and b) a He gas flow of $150 \mathrm{~mL} / \mathrm{min}$ for $60 \mathrm{~min}$. For both experiments, the MC simulations of a diffusion controlled deposition (red lines) are shown, assuming $-\Delta \mathrm{H}_{\mathrm{ads}}{ }^{\mathrm{red}} \mathrm{ae}(\mathrm{Hg})=$ $85 \mathrm{~kJ} / \mathrm{mol}$ and a $95 \%$ surface coverage with red a-Se. 


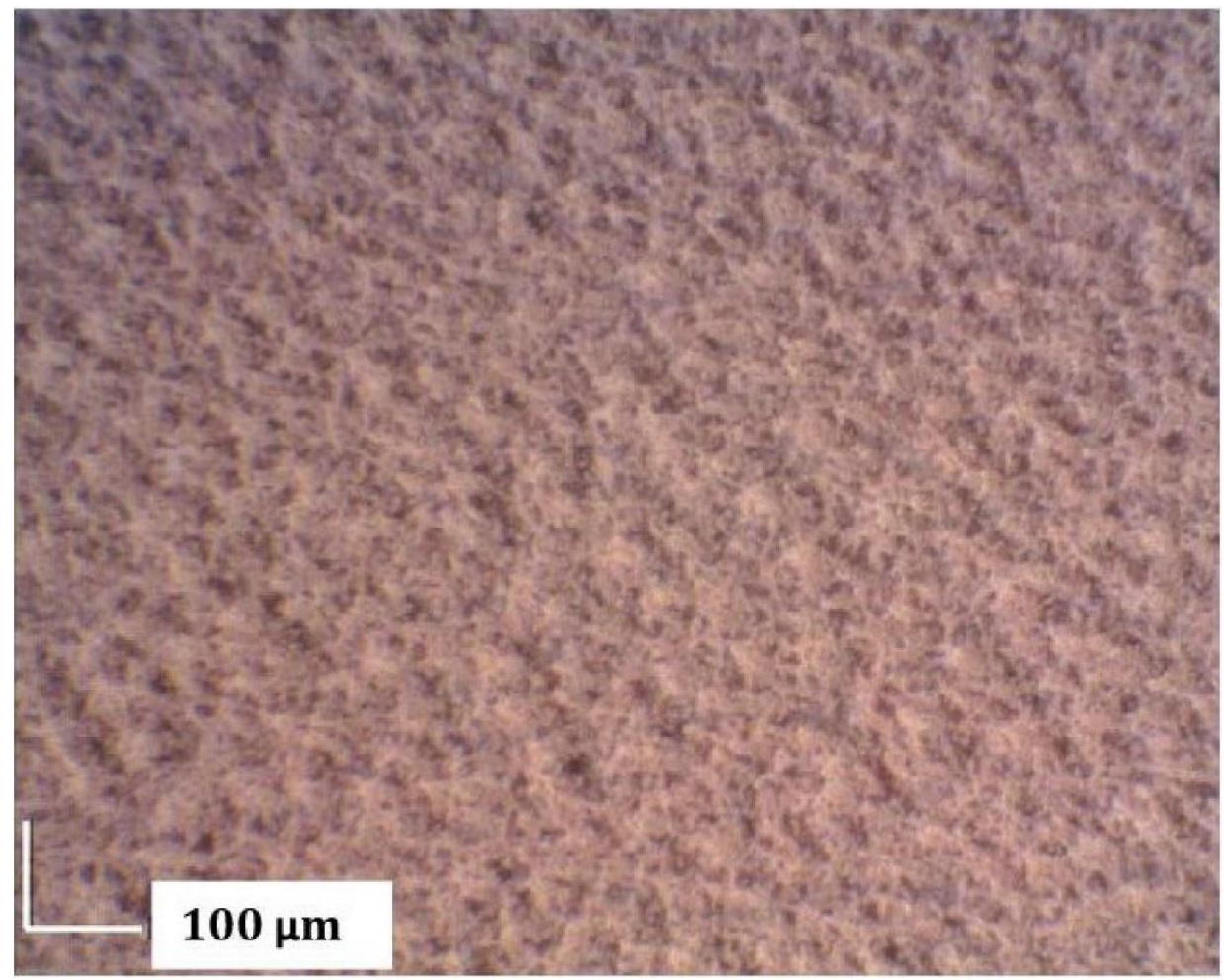

Fig. 4 Optical microscopy image of a typical red a-Se coverage (scale bar: $100 \mu \mathrm{m}$ ) under top illumination with a white light emitting diode. RGB analysis with the Origin 2015 software package allowed for an estimation of a $95 \%$ coverage of the stationary surface with red a-Se.

\subsubsection{Hg interaction towards trigonal selenium}

No ${ }^{197} \mathrm{Hg}$ deposition was observed on the t-Se stationary phase at room temperature. MC simulations were performed, assuming $40 \%$ coverage of the quartz column surface with $\mathrm{t}-\mathrm{Se}$. This coverage was again determined based on an optical microscopy examination (see Fig. 5). An upper limit for the adsorption enthalpy of $-\Delta \mathrm{H}_{\mathrm{ads}}{ }^{\mathrm{t}-\mathrm{Se}}(\mathrm{Hg})<60 \mathrm{~kJ} / \mathrm{mol}$ was derived. The lower adsorption of $\mathrm{Hg}$ on the $\mathrm{t}-\mathrm{Se}$ surface in comparison to the red amorphous one is the consequence of a different structure of the chromatographic selenium surface. In fact, the red a-Se metastable phase is composed of short selenium chains and $\mathrm{Se}_{\mathrm{n}}$-ring clusters, which are more unstable (and hence, reactive) than the long polymeric Se chains composing the trigonal phase [27]. 


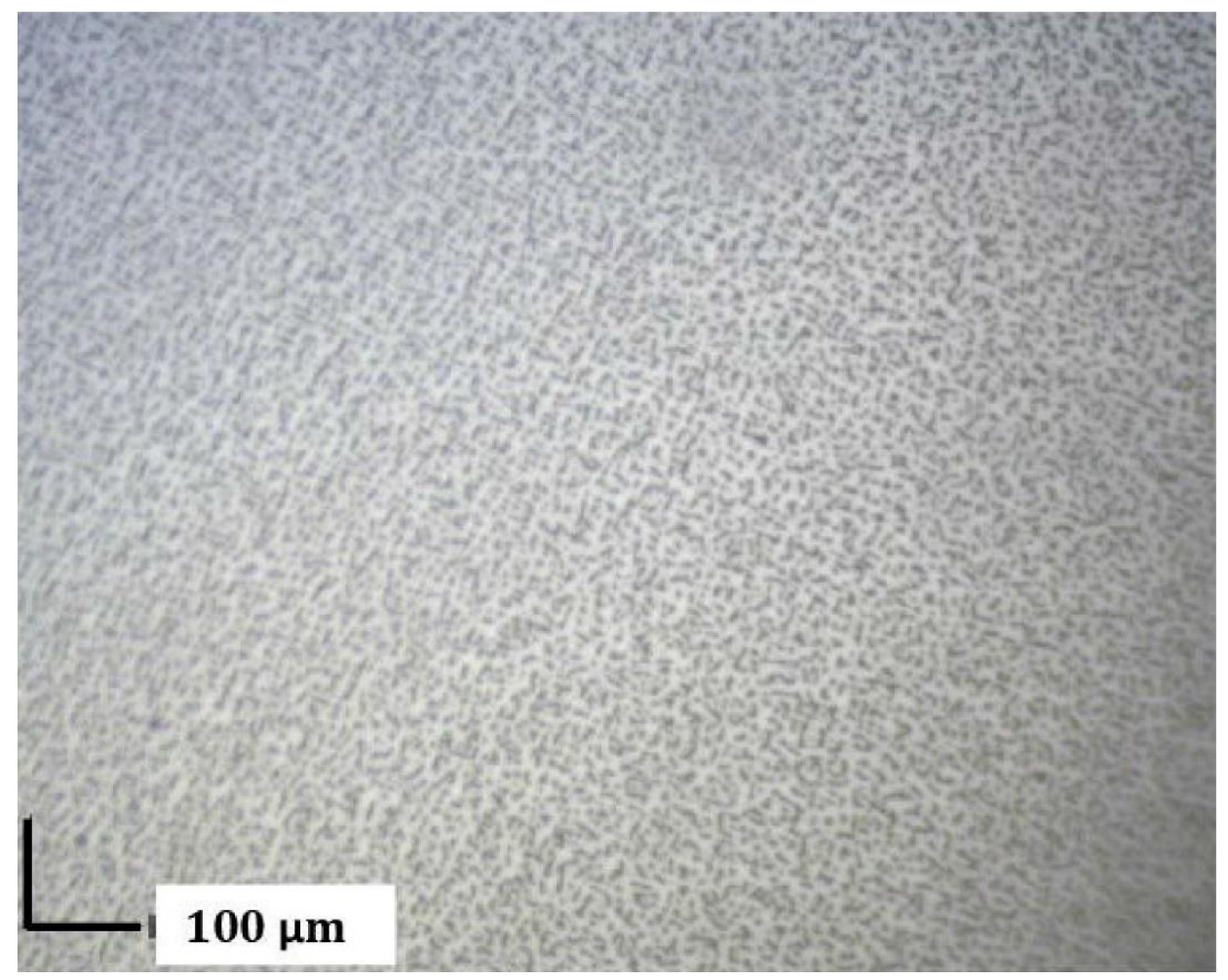

Fig. 5 Optical microscopy image of a typical trigonal selenium surface (scale bar: $100 \mu \mathrm{m}$ ). A 50 W tungsten microscope light was used for back-illumination. The ratio of the dark spots (covered surface) to white background (uncovered surface) allowed for an estimation of $40 \%$ coverage of the stationary surface with t-Se.

\subsection{On-line chromatography}

\subsubsection{Experiment A}

An average $(5 \pm 3) \%$ deposition of the total amount of ${ }^{183-185} \mathrm{Hg}$ was observed on the red a-Se covered detectors in five separate experiments (Fig. 6), revealing an advanced spontaneous crystallization of the red amorphous allotrope. This structural change could not be detected with conventional analytical instrumentation like X-ray diffraction or scanning electron microscopy (see Fig. 7), thereby backing the hypothesis of a crystallization process occurring at the selenium surface $[25,40]$. Since the detectors were not thermally insulated during the storage time, a crystallization process due to environmental temperature changes cannot be excluded. The introduction of a randomly selected "coverage factor" (normally distributed) in the MC 
simulation's code allowed for simulating the chemical interaction of $\mathrm{Hg}$ with a surface made of red amorphous selenium and trigonal selenium in different percentages. Further information on the single steps of the MC simulation process can be found in [29]. The MC simulation output which reflects best the averaged experimental data is shown in Fig. 8. This was obtained assuming $98 \%$ of the red a-Se surface being transformed into a crystalline Se allotrope with an adsorption enthalpy $-\Delta \mathrm{H}_{\text {ads }}{ }^{\mathrm{t}} \mathrm{Se}(\mathrm{Hg})=50 \mathrm{~kJ} / \mathrm{mol}$. This is indeed an indication about the presence of a superficial layer of the trigonal allotrope covering the red amorphous selenium underneath. Since the black amorphous Se covered PIN diodes were kept under identical storage conditions such as the red amorphous ones, an advanced crystallization process at the surface of the black metastable allotrope is expected. The latter is confirmed by the $\mathrm{Hg}$ deposition pattern, which is best described in the MC simulations by setting the reactivity of mercury toward black amorphous Se the same as for a trigonal Se surface. The adsorption enthalpies for mercury on gold and quartz surfaces were taken from [39].

No influence on the electronic performance of the PIN diodes covered with different Se allotropes was observed.

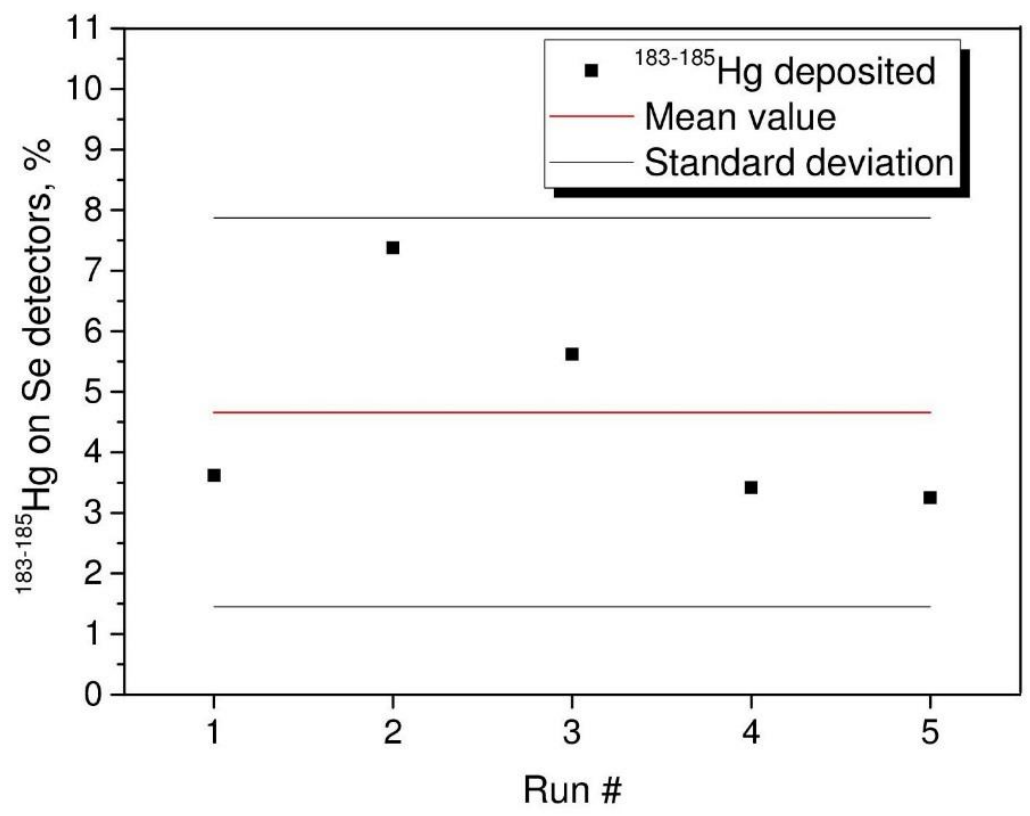


Fig. $6{ }^{183-185} \mathrm{Hg}(\%)$ deposited on the red a-Se covered PIN diodes for each run of Experiment A. Average: $(5 \pm 3) \%$, for a $95 \%$ confidence interval.

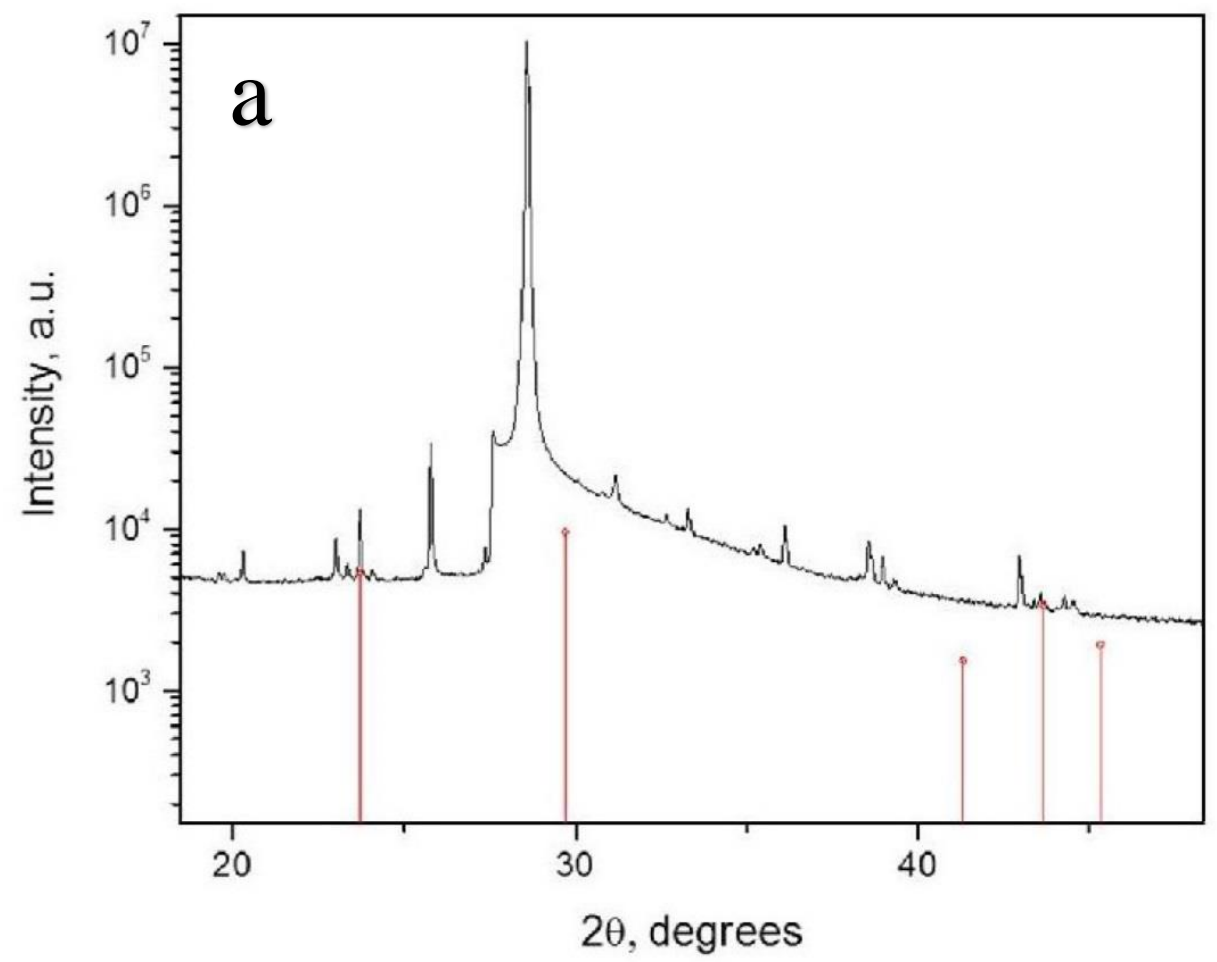



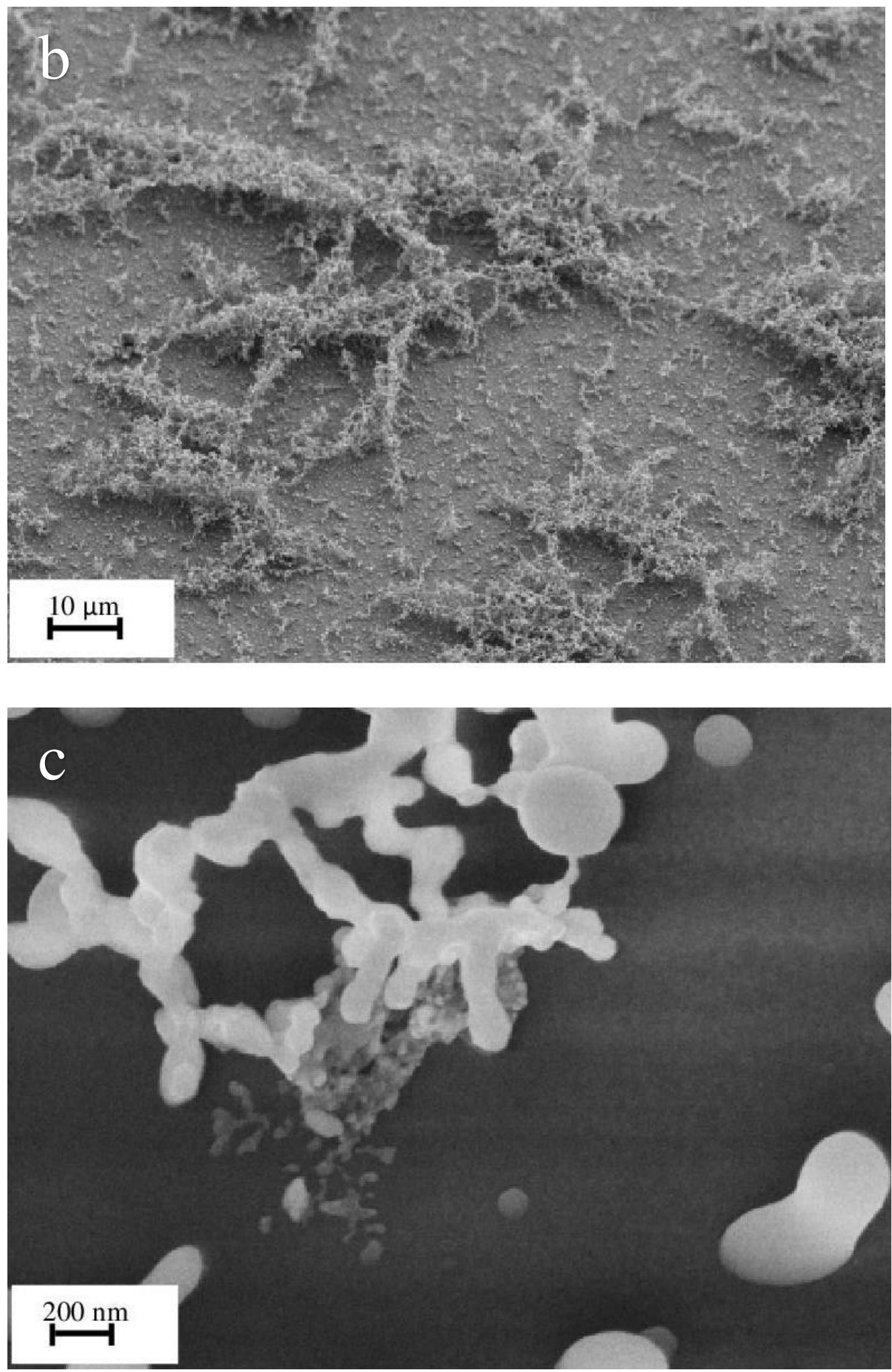

Fig. 7 a) silicon PIN diode covered with red a-Se, aged for 5.5 weeks, was analyzed by a) X-ray diffraction (the t-Se peaks (red lines) cannot be identified due to the high background signals, b) 
scanning electron microscopy (scale bar: $10 \mu \mathrm{m}$ ), and c) scanning electron microscopy (scale bar: $200 \mathrm{~nm}$ ). No crystallites, indicating t-Se, are observed on a micrometer and nanometer scale.

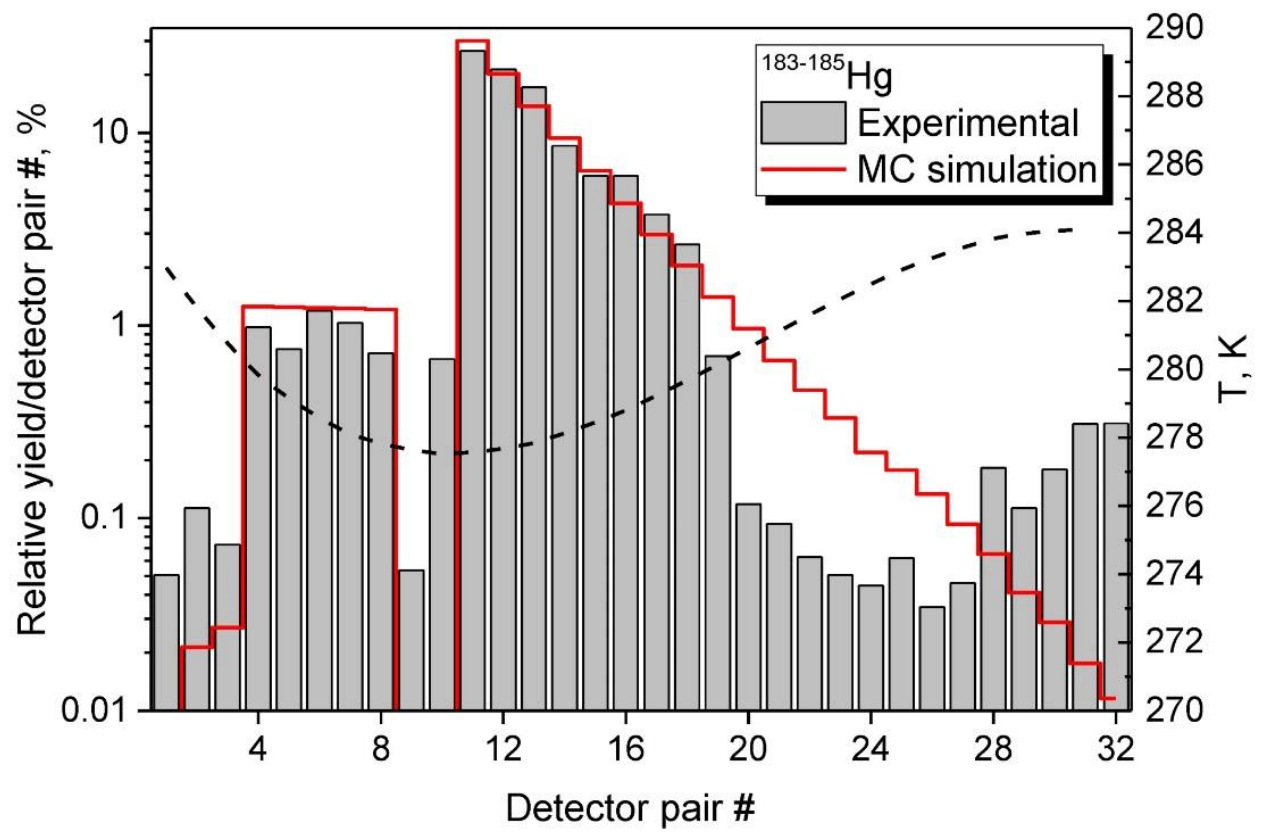

Fig. 8 Average chromatographic deposition pattern of ${ }^{183-185} \mathrm{Hg}$ (grey bars) in the COLD array. The MC simulation (red line) is in good agreement with the experimental results, assuming $\Delta \mathrm{H}_{\text {ads }}{ }^{\text {red a-Se }}(\mathrm{Hg})=85 \mathrm{~kJ} / \mathrm{mol}$ and $-\Delta \mathrm{H}_{\mathrm{ads}}{ }^{\mathrm{t}}{ }^{\mathrm{Se}}(\mathrm{Hg})=50 \mathrm{~kJ} / \mathrm{mol}$, as well a $95 \%$ PIN diode surface coverage with $\mathrm{Se}$ (93\% t-Se, $2 \%$ red a-Se, $5 \%$ quartz). The established temperature profile (dashed line) is shown as well. Due to a minor surface contamination on the gold covered detectors, a difference between the experimental deposition and the MC simulation can be observed from detector \#19 onwards, with an estimated loss of $\approx 3 \%$ of the total yield of ${ }^{183-185} \mathrm{Hg}$. Note that the observation of ${ }^{183-185} \mathrm{Hg}$ on the uncovered detectors \#1, \#9, and \#10 (i.e., quartz surface) is partly attributed to the decay of ${ }^{183-185} \mathrm{Hg}$ deposited on neighboring detectors emitting $\alpha$-particles under shallow angles with an estimated probability of $\leq 1 \%$, which was not considered in the simulation.

\subsubsection{Experiment B}


The ${ }^{183-185} \mathrm{Hg}$ deposition pattern for Experiment B is shown in Fig. 9. The MC simulation agrees well with the experimental results assuming $-\Delta \mathrm{H}_{\text {ads }}{ }^{\text {red a-Se }}(\mathrm{Hg})=85 \mathrm{~kJ} / \mathrm{mol}$ and $-\Delta \mathrm{H}_{\text {ads }}{ }^{\mathrm{t}-\mathrm{Se}}(\mathrm{Hg})=52$ $\mathrm{kJ} / \mathrm{mol}$, with a surface composition of maximum $2 \%$ of red a-Se and $93 \%$ of the trigonal phase. A $\approx 2 \%$ deposition of the total amount of ${ }^{183-185} \mathrm{Hg}$ was observed on the crystallized red a-Se covered detectors, showing that an increase of the working temperature to $\mathrm{T} \approx+45^{\circ} \mathrm{C}$ did not affect the kinetic interaction rate of mercury with the trigonal allotrope. No difference is observed in terms of the mercury interaction with the PIN diodes covered with a $100 \mu \mathrm{g} / \mathrm{cm}^{2}$ Se layer and those covered with a $200 \mu \mathrm{g} / \mathrm{cm}^{2}$ layer. This is a further confirmation of the hypothesis of a surface crystallization process rather than a crystallization of the entire selenium bulk material.

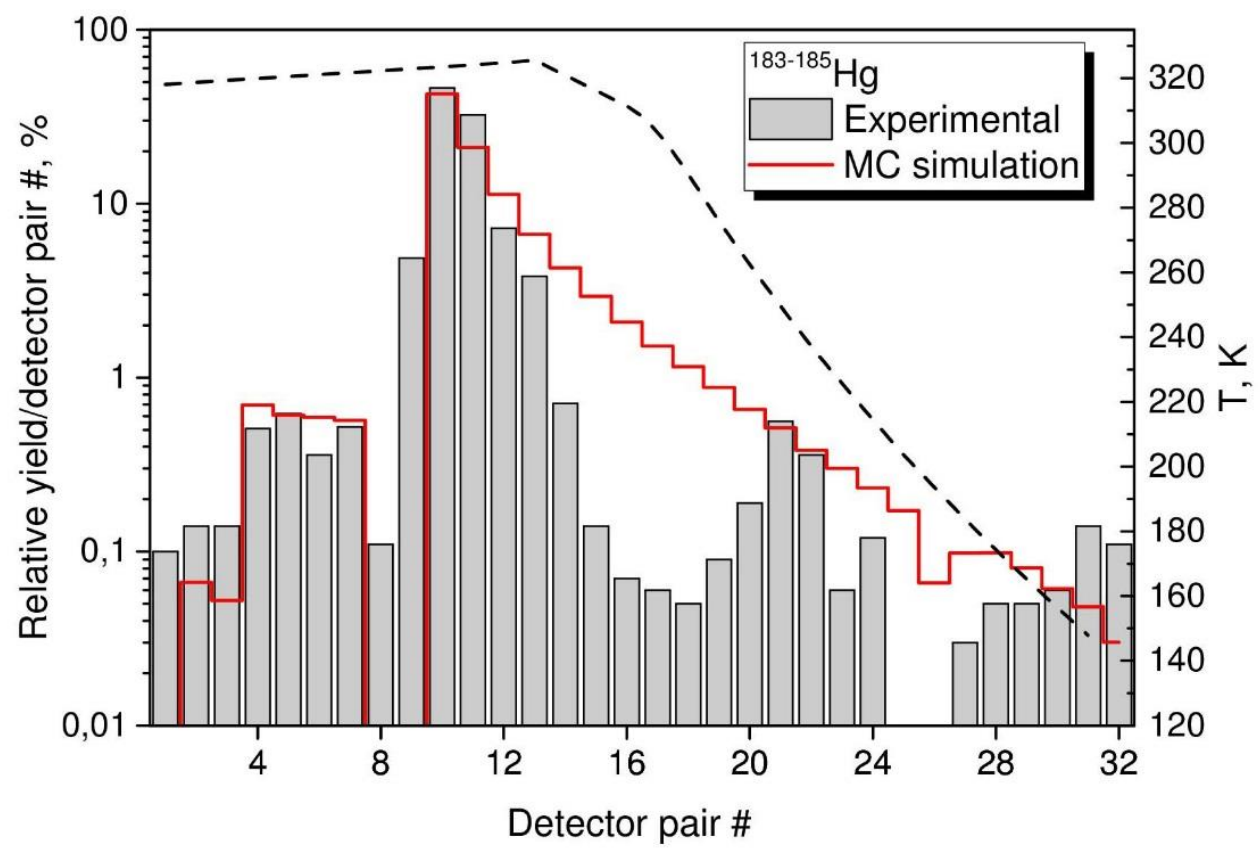

Fig. $9{ }^{183-185} \mathrm{Hg}$ deposition pattern (grey bars) for the Experiment B. The applied temperature profile is indicated (dashed line). Below $-80^{\circ} \mathrm{C}$, i.e., from detector $\# 25$ onwards, a layer of ice is assumed to cover the detectors. The corresponding MC simulation (red line) is in good agreement with the experimental results assuming $-\Delta \mathrm{H}_{\text {ads }}{ }^{\text {red a- }-\mathrm{Se}}(\mathrm{Hg})=85 \mathrm{~kJ} / \mathrm{mol}$ and $-\Delta \mathrm{H}_{\text {ads }}{ }^{\mathrm{t}-\mathrm{Se}}(\mathrm{Hg})=52$ $\mathrm{kJ} / \mathrm{mol}$, with a surface composition of maximum $2 \%$ red amorphous selenium and $93 \%$ trigonal selenium. Due to a minor contamination of the Au-covered detectors, a difference can be observed between the experimental deposition and the MC simulation: Starting from detector \#14 onwards, 
an estimated loss of $\approx 10 \%$ of the total ${ }^{183-185} \mathrm{Hg}$ yield occurred. Note here that the observation of ${ }^{183-185} \mathrm{Hg}$ on the uncovered detectors \#1, \#9, and \#10 (i.e., quartz) is partly a result of the decay of ${ }^{183-185} \mathrm{Hg}$, being deposited on neighboring detectors.

\section{Conclusions}

The adsorption behavior of long-lived $\left({ }^{197} \mathrm{Hg}\right)$ and short-lived $\left({ }^{183-185} \mathrm{Hg}\right)$ mercury isotopes on surfaces covered with different Se allotropes was investigated by off-line and on-line gas chromatographic studies. The off-line experiments revealed a strong reversible interaction between mercury and the red a-Se allotrope. A lower limit for the adsorption enthalpy of $-\Delta \mathrm{H}_{\mathrm{ads}}{ }^{\mathrm{red}} \mathrm{a}-\mathrm{Se}(\mathrm{Hg})$ $>85 \mathrm{~kJ} / \mathrm{mol}$ was determined. On trigonal selenium an upper limit for the interaction energy of $\Delta \mathrm{H}_{\mathrm{ads}}^{\mathrm{t}-\mathrm{Se}}(\mathrm{Hg})<60 \mathrm{~kJ} / \mathrm{mol}$ was deduced, pointing to a weak reversible adsorption process between $\mathrm{Hg}$ and the thermodynamic stable Se allotrope. The different adsorption interactions of mercury on the two allotropes of selenium allowed for monitoring the conversion grade of the metastable amorphous selenium to the trigonal one during the on-line experiments. In this manner, more than $90 \%$ of the surface of the selenium covered PIN diodes used in the on-line experiments was determined to be trigonal selenium, showing after 5.5 weeks of storage an advanced crystallization of the initial amorphous selenium interface. It was also observed that the varied thickness of the Se layers deposited on the PIN diodes did neither influence the crystallization kinetics nor the reactivity toward mercury. No increase of the mercury adsorption on the Se covered detectors was observed for temperatures up to approximately $+45^{\circ} \mathrm{C}$. This fact points to a severe kinetic hindrance of the interaction between mercury and trigonal selenium.

The application of red a-Se and t-Se coated PIN diodes in future experiments with $\mathrm{Cn}$ and $\mathrm{Fl}$ appears feasible. The inhibition of the crystallization process of the red a-Se surfaces is essential to perform gas-chromatographic experiments with a pure red a-Se phase. This can be achieved for example by storing the red a-Se coated diodes in darkness, below room temperatures, under vacuum conditions. PIN diodes covered with t-Se can be applied as well in comparative chemical studies with $\mathrm{Hg}, \mathrm{Cn}$, and $\mathrm{Fl}$. In case the interaction of $\mathrm{Cn}$ and $\mathrm{Fl}$ with a t-Se surface is explored through isothermal gas-chromatography, the coupling of the t-Se coated detectors to a thermochromatographic channel composed of Au covered diodes is recommended, as it was used 
in $[6,8]$. In fact, in case of a hypothetic weak interaction of $\mathrm{Cn}$ and $\mathrm{Fl}$ with the t-Se surface (alike the $\mathrm{Hg}$ / trigonal Se system), the adsorption and the detection of both SHEs is anyway provided by the Au coated diodes. Due to the high thermodynamic stability of the trigonal Se allotrope, thermochromatographic adsorption experiments applying a negative gradient of temperature can be conducted as well, allowing hence for a direct comparison of the chemical behavior of $\mathrm{Hg}, \mathrm{Cn}$, and Fl.

\section{References}

1. Oganessian $\mathrm{Y}$ et al (2006) Synthesis of the isotopes of elements 118 and 116 in the ${ }^{249} \mathrm{Cf}$ and

${ }^{245} \mathrm{Cm}+{ }^{48} \mathrm{Ca}$ fusion reactions. Phys Rev C. 74:044602-1-044602-9

2. Pyykko P (1988) Relativistic effects in structural chemistry. Chem Rev. 88:563-594

3. Hoffman D (2012) Development, relevance, and application of "atom-at-a-time" techniques. J Radioanal Nucl Chem. 291:5-11

4. Gäggeler H, Türler A (2014) Gas-phase chemistry of superheavy elements. In: Schädel M (Ed.) The Chemistry of Superheavy Elements, 2nd edn. Springer, Berlin, Heidelberg, pp 415-483

5. Eichler R (2015) Superheavy element chemistry. In: Greiner W (Ed.) Nuclear Physics: Present and Future, 2nd edn. Springer, Switzerland, pp 33-43

6. Eichler R et al (2007) Chemical characterization of element 112. Nature. 447:72-75

7. Pershina $V$ et al (2009) Theoretical predictions of adsorption behavior of elements 112 and 114 and their homologs $\mathrm{Hg}$ and $\mathrm{Pb}$. J Chem Phys. 131:084713-1-084713-8

8. Eichler R et al (2010) Indication for a volatile element 114. Radiochim Acta. 98:133-139

9. Yakushev A et al (2014) Superheavy element flerovium (element 114) is a volatile metal. Inorg Chem. 53:1624-1629 
10. Krishnan S V et al (1994) Sorption of elemental mercury by activated carbons. Environ Sci Technol. 28:1506-1512

11. Sinha et al (1972) Removal of mercury by sulfurized carbons. Carbon. 10:754-756

12. Schädel M, Shaughnessy D (2014) The Chemistry of Superheavy Elements. Springer, Berlin, Heidelberg

13. Steinegger $\mathrm{P}$ et al (2016) Vacuum Chromatography of $\mathrm{Tl}$ on $\mathrm{SiO}_{2}$ at the Single-Atom Level. J Phys Chem C 120:7122-7132.

14. Eichler B, Eichler R (2014) Thermochemical Data from Gas-Phase Adsorption and Methods of Their Estimation. In: Schädel M, Shaughnessy D (Eds.) The Chemistry of Superheavy Elements, 2nd edn. Springer, Berlin, Heidelberg, pp. 375-413

15. Eichler B (2003) Volatilization behavior of transactinides from metal surfaces and melts (thermochemical calculation). Paul Scherrer Institut Report 2003, Villigen, Switzerland

16. Gaston N et al (2007) Is Eka-Mercury (Element 112) a Group 12 Metal? Angew Chem Int Ed. 46:1663-1666

17. Hermann A et al (2010) Spin-orbit effects in structural and electronic properties for the solid state of the group-14 elements from carbon to superheavy element 114. Phys Rev B. 82:155116$1-155116-8$

18. Ralston N (2008) Nanomaterials: Nano-selenium captures mercury. Nat Nanotechnol. 3:527528

19. Robertson J (1976) A new model for the structure of amorphous selenium. Phil Mag. 34:1331

20. Caprion D et al (2000) Structure and relaxation in liquid and amorphous selenium. Phys Rev B. $62: 3709-3716$

21. Muñoz A (1987) Influence of the substrate on the crystallization kinetics of vapor-deposited amorphous selenium films. Thin Solid Films. 149:L73-L76 
22. Steudel R, Strauss E (1984) Homocyclic selenium molecules and related cations. In: Emeleus H J and Sharpe A G (Eds.) Advances in Inorganic Chemistry and Radiochemistry, Academic Press, Orlando, pp 135-166

23. Misawa M, Suzuki S (1978) Ring-chain transition in liquid selenium by a disordered chain model. J Phys Soc Jpn. 44: 1612-1618.

24. Kim K et al (1974) Crystallization of amorphous selenium films. II. Photo and impurity effects. J Appl Phys. 45:3447-3452

25. Kim K et al (1973) Crystallization of amorphous selenium films. I. Morphology and kinetics. J. Appl Phys 44:5237-5244

26. Minaev V (2005) Structural and phase transformations in condensed selenium. J Optoelectron Adv M. 7:1717-1741

27. Cooper W (1969) The Physics of Selenium and Tellurium. Pergamon Press, Oxford

28. Chiera $\mathrm{N}$ et al (2015) Vapor deposition coating of fused silica tubes with amorphous selenium. Thin Solid Films. 592:8-13

29. Zvara I (1985) Simulation of thermochromatographic processes by the Monte Carlo method. Radiochim Acta. 38:95-102

30. Haynes W (2016) CRC handbook of chemistry and physics. CRC press, Taylor and Francis group, New York

31. Barin I (1990) Thermochemical data of pure elements. VCH Verlagsgesellschaft $\mathrm{mbH}$, Weinheim

32. Gobrecht H (1970) Transformations of red amorphous and monoclinic selenium. J. Phys. Chem. Solids. 31:2145-2148

33. Pershina V et al (2005) Relativistic effects on experimentally studied gas-phase properties of the heaviest elements. Chem Phys. 311:139-150

34. Eichler R et al (2007) Chemical properties of element 112. Nature 447:72-75 
35. Soverna $\mathrm{S}$ et al (2005) Thermochromatographic studies of mercury and radon on transition metal surfaces. Radiochim Acta 93:1-8

36. Ziegler J (2010) SRIM-The stopping and range of ions in matter . Nucl Instrum Meth B. 268:1818-1823.

37. Düllmann C et al (2002) IVO, a device for in situ volatilization and on-line detection of products from heavy ion reactions. Nucl Instrum Meth A. 479:631-639

38. Siiskonen $\mathrm{T}$ et al (2005) Advanced simulation code for alpha spectrometry. Nucl Instrum Meth A. 550:425-434.

39. Soverna S (2004) Attempt to chemically characterize element 112. Doctoral Thesis, Universität Bern.

40. Legros A et al (1995) Effect on water impurity on the crystallization of vacuum evaporated Se. J Appl Phys. 78:3048-3051 